\title{
Longitudinal Analysis of Adolescent Growth of Ladino and Mayan School Children in Guatemala: Effects of Environment and Sex
}

BARRY BOGIN, MAUREEN WALL, AND ROBERT B. MACVEAN Department of Behavioral Sciences, University of Michigan, Dearborn, Michigan 48128 (B.B., M.W.) and Universidad del Valle de Guatemala, Apartado Postal No. 82, Guatemala City, Guatemala (R.B.M.)

\section{KEY WORDS Adolescent growth, Maya Indians, Guatemala}

\begin{abstract}
The rate of growth in height and the timing of adolescent growth events are analyzed for two samples of Guatemalan children. One sample includes Mayan school children, 33 boys and 12 girls between the ages of 5.00 to 17.99 years, living under poor conditions for growth and development. The second sample includes ladino children, 78 boys and 85 girls of the same age range, living under favorable conditions for growth. The PreeceBaines model I function is used to estimate mean values for rates and timing of childhood and adolescent growth events for the two groups. Significant statistical contrasts (t-tests) of these means show Mayan boys reach the age of "take-off" (TO; the onset of the adolescent growth spurt) 1.45 years later, achieve peak height velocity (PHV) 1.68 years later, and continue growing for about 2.0 years longer than do the ladino boys. Despite the Mayan boys' increased duration for growth they grow significantly more slowly than the ladinos. Mayan boys are $6.60 \mathrm{~cm}$ shorter than ladinos at the age of TO and are estimated to be $7.71 \mathrm{~cm}$ shorter than the ladinos at adulthood. Mayan girls reach the age of TO 0.93 years later than do the ladina girls, but the two groups do not differ in the age at PHV or the age at adulthood. The mean height of Mayan girls is significantly less than that of ladinas at the age of TO $(6.5 \mathrm{~cm})$, and this difference increases to an estimated $11.14 \mathrm{~cm}$ at adulthood. Possible causes of these ethnic and sex-related differences in amounts and rates of growth are discussed in relation to hypotheses about the genetic and environmental determinants of human development. 1992 Wiley-Liss. Inc.
\end{abstract}

The population of Guatemala is composed of two major ethnic groups, Mayans and ladinos. Mayans are the cultural descendants of the pre-Colombian inhabitants of southern Mexico and Central America. Mayans often speak one of the 22 Native American languages used in Guatemala and dress in distinctive clothing. Many aspects of Mayan social organization, kinship, calendars, religion, and other sociocultural behaviors are also of pre-Colombian origin (Annis, 1987; Carmack, 1988; Tedlock, 1982). Ladinos, the cultural descendants of the Spanish conquistadores, are native-born Guatemalans who speak Spanish and follow a Spanishderived way of life, i.e., style of dress, religion, kinship (Siverts, 1969).
Growth data for Mayan children have been published in this century based upon cross-sectional surveys (Bogin and MacVean, 1984; Mendez and Berhorst, 1963; Sabharwal et al., 1966). More recently, the first mixed-longitudinal analysis of growth in height during childhood (5 to 14 years of age) of Mayan children was published (Bogin et al., 1989). All of these studies find Mayan children to be shorter, on average, at all ages than ladino children. While there may be some genetic cause for part of the difference in stature, a poor environment for growth is often considered as

Received May 2, 1991; accepted May 26, 1992 
the major determinant of the small size of Mayan children compared with ladinos. Previous research demonstrates that in contrast to ladino children, Mayan children suffer from higher average rates of undernutrition, morbidity from infectious and chronic disease, and mortality. Even when compared with ladino children from low socioeconomic status (SES) families, Mayan children are, on average, more poorly nourished and less healthy (Bogin and MacVean, 1984; Bossert and Peralta, 1987; INCAP, 1969, 1989; May and McLellan, 1972).

Some compensation for reduced growth during childhood may occur during adolescence by altering either the time of onset, intensity, or duration of the growth spurt (Bogin, 1988; Largo et al., 1978). The mixedlongitudinal analysis of Mayan and ladino growth indicated that Mayan boys had a significantly later age for the onset of the adolescent growth spurt compared with ladino boys from well-to-do families. Mayan girls, in contrast, did not appear to differ from ladina girls in the timing of the onset or peak velocity of the adolescent spurt. These observations on rate of growth are tentative due to: 1) growth data limited to ages 5 to 14 years, thus not having data during much of adolescence; and 2) the well known difficulty of using cross-sectional or mixed-longitudinal data to calculate the timing of adolescent growth events (Boas, 1930). Only longitudinal measurements of a child during the years of adolescence can indicate adequately the age of onset of the adolescent spurt (often called "take-off" or TO), the age of peak height velocity (PHV), and the velocity of growth at TO and PHV.

Longitudinal data are now available for a small sample of Mayan children through age 17 years. The purpose of the present study is to estimate more precisely the age of TO and PHV, the velocity of growth at TO and PHV, and other adolescent growth parameters for the Mayans and to compare these values with those for healthy and well-nourished Guatemalan ladinos. For this analysis we use the mathematical model of adolescent growth developed by Preece and Baines (1978). The results of this analysis are used to examine two hypotheses concerning the effect of genetic and environmental determi- nants of growth and development. One hypothesis is that growth during childhood (prior to "take-off") is relatively more sensitive to environmental factors and growth during adolescence is determined to a greater extent by genetic factors. The second hypothesis is that girls are better "buffered" against negative environmental influence of growth than are boys.

\section{MATERIALS AND METHODS}

\section{Subjects}

The Mayan sample is derived from the Longitudinal Study of Child and Adolescent Development conducted by the Universidad del Valle de Guatemala. The individuals selected for the present analysis were students attending two schools in a village 22 $\mathrm{km}$ from Guatemala City (the capital of the country). The village has a population of about 6,000 people and more than $95 \%$ are ethnically Mayan; most of the residents are Kakchiquel language speakers, women wear home-made "Mayan-style" clothing, the practice of Mayan medicine is common, and while most residents profess to follow Catholic or Protestant religions, many traditional Mayan religious customs and festival days are also observed (Bogin, field observations 1979-1990; Pettersen, 1976).

One of the schools is a public elementary school with grades kindergarten to sixth. The school conducts classes from 8 AM to noon from Monday to Friday during the school year. After school younger children return home to play or perform small household chores, while older children work. In 1980 there were 1,385 children in the village eligible to attend this school, but only 850 children $(61 \%)$ were enrolled. Growth status of this school sample has been described (Bogin and MacVean, 1984; Bogin et al., 1989). The other school is a private secondary school that operates three grades. The annual tuition for this school was 51.50 quetzales (about US\$13.00) in 1989), which represents about $2 \%$ of median annual family income for all of Guatemala (median family income for the village is not known). This fee is supplemented by funds from national philanthropic agencies and local community organizations. About 150 students of both 
sexes attend the school for one half-day session. Before or after school most of the students work at home or at wage-paying jobs. Growth data from this secondary school sample have not been published previously.

The ladino sample attends a private feepaying school in Guatemala City, one of the most expensive schools in the country. The school population includes Guatemalan, European, and North American nationals. The sample selected from this school population is limited to Guatemalan nationals whose parents and grandparents were born in Guatemala and have Spanish surnames. The school day is from $8 \mathrm{AM}$ to $3 \mathrm{PM}$ and after school the students enjoy a lifestyle similar to upper-middle class children and youth living in the United States or Western Europe. Cross-sectional and longitudinal analyses of the growth of this ladino sample have been published (Bogin and MacVean, 1978, 1983; Bogin et al., 1989, 1990; Johnston et al., 1973).

A family member of each of the children participating in the Longitudinal Study completes a questionnaire to ascertain socioeconomic status (SES) of the family. The questionnaire includes a variety of items, but a composite score for parental education and occupation prove to be sufficient to define SES (Bogin and MacVean, 1983; Bogin et al., 1989). The composite score range is 4 to 15 points; the ladino sample has a mean value of 12.21 ( $\mathrm{sd}=3.39, \mathrm{n}=225$ ) and the Mayan primary school sample has a mean of 4.96 ( $\mathrm{sd}=0.57, \mathrm{n}=810$ ). The difference between the mean scores is statistically significant $(P<.001)$ and is paralleled by several important differences in the biosocial environment for growth and development between the samples. The high SES ladino school provides programs for physical education, medical screening, and planned lunches that help to ensure that these children are well nourished and healthy. The home environment of the ladino sample is similarly privileged. Median values for amounts and rates of growth in height and weight of the ladinos are essentially the same as that for the NCHS reference sample of the United States. Body composition analysis (fatness and muscularity) also affirms that the ladinos are well nourished (Bogin and MacVean, 1981; Bogin and Sullivan, 1986; Johnston et al., 1984). The low SES Mayan sample lives in a village with no safe supply for drinking water, an irregular supply of water, and inadequate means for waste disposal. The parents of the Mayan children are employed, predominantly, as tailors or seamstresses by local clothing manufacturers or are self-employed street vendors of textiles and agricultural produce. Textile workers in this town are usually paid "piecework" wages, e.g., about $\$$ US0.25 for a finished blouse or shirt. There is one public health clinic in the village, and the treatment of infants and preschool children with clinical undernutrition is common. Body composition analysis of the children attending the public school finds that, on average, they exhibit signs of chronic mildto-moderate undernutrition (Bogin and MacVean, 1984).

\section{Sample selection}

Children attending the Mayan schools span an age range of 5.0 to 17.99 years. Each year all children in the first, second, fourth, and sixth grades of primary school and in the first and third grades of secondary school are measured. Thus, an ideal longitudinal record for a Mayan child would include six measurements over a nine year period Some children repeat one or more grades, and these individuals may have seven or eight measurements. Also, some children enter the study after the first grade, are absent from school during some of the years of measurement, or drop out of school and have less than six data points. Initially, 45 boys and 13 girls were selected who met the fol lowing criteria: 1 ) at least three longitudinal measurements; and 2) at least two measurements between the ages of 14 and 17 years. A satisfactory application of the PreeceBaines function was possible for only 33 boys and 12 girls. Two boys and one girl were dropped because the function produced negative growth increments between the ages at take-off and peak height velocity. Direct analysis of the original growth data produced only positive increments, thus these three cases were clearly not amenable for analysis by the Preece-Baines function. The other 10 boys were dropped because the 
mean error sum of squares of the residuals (the "goodness of fit" of the function to the empirical data) was greater than $2.99 \mathrm{~cm}$, an arbitrarily selected criterion. For all of the dropped cases the cause of the poor fit of the function to the data was due to missing data points, especially at or after peak height velocity. The Preece-Baines function is sensitive to missing data at these times (Preece and Metcalf, 1985).

All children attending the high SES $l a$ dino school are measured once a year, normally during the same week every August. The sample includes 78 boys and 85 girls with at least 8 annual measurements, but many have 9 or 10 . The absolute age range from first to last measurement is 5.0 to 17.99 years, and in all cases spans the years of adolescence. Measurement procedures are the same at both the Mayan and ladino schools and are performed by the same group of technicians. Procedures have been described by Bogin and MacVean (1978, 1984) and generally follow the methods of Cameron (1986). The technicians were trained by the senior author. Periodic assessments show that intra-observer reliability coefficients are greater than 0.90 , while inter-observer reliability coefficients average 0.74 . No systematic trends in the error correlations are apparent.

\section{Curve fitting}

Preece and Baines (1978) developed a series of mathematical models of growth from mid-childhood through adolescence. These models assume the shape of the growth curve during this period of life and, essentially, "force" empirical growth data for a child to conform to the assumed shape. This is done by fitting mathematically the longitudinal data to the model using a non-linear least-squares estimation technique. In the present analysis we use the non-linear optimization program developed by Brown (1983) for fitting the Preece-Baines model I function on an Apple II computer. The function contains five mathematical parameters and is particularly useful for analyzing adolescent growth since four of the parameters correlate with amount or rate of growth at the onset of the adolescent growth spurt or during the spurt. The fifth parameter correlates with adult height.

The Preece-Baines model I function is given as:

$$
\begin{aligned}
& \mathbf{h}_{\mathrm{t}}=\mathrm{h}_{1}-2\left(\mathrm{~h}_{1}-\mathrm{h}_{\mathrm{c}}\right) /\left\{\exp \left[\mathrm{s}_{0}(\mathrm{t}-\mathrm{c})\right]+\right. \\
& \left.\exp \left[\mathrm{s}_{1}(\mathrm{t}-\mathrm{c})\right]\right\}
\end{aligned}
$$

where $h_{t}$ is height at time $t, h_{1}$ is final (adult) height, $s_{0}$ and $s_{1}$ are rate constants, $c$ is a time constant, and $h_{c}$ is height at $t=c$. Although the model was derived empirically, Preece and Baines were able to correlate each of the five parameters of the model with "biological" events that occur during growth. The rate constants $s_{0}$ and $s_{1}$ correlate with minimal prepubertal velocity of growth (velocity at "take-off" or TO) and velocity at peak height velocity (PHV), respectively. Time $c$ has a high correlation with age at $\mathrm{PHV}$ and $\mathrm{h}_{\mathrm{c}}$ correlates with height at PHV.

The Preece-Baines function is fitted to the longitudinal measurements of an individual through a series of iterations, each iteration minimizing the mean sum of squares for the residual error of the mathematical parameters. The iterative procedure of the Brown (1983) program stops when the residual error mean sum of squares reaches 0.001 or when 400 iterations are completed.

The Brown (1983) program also estimates a series of biological parameters derived from the mathematical parameters of the model, such as age at $\mathrm{TO}$, growth velocity at TO, age at PHV during the spurt, and the value of $\mathrm{PHV}$. The mean values for the mathematical and biological parameters were calculated separately for boys and girls. These means were used to construct mean-constant distance and velocity curves of growth in height.

\section{RESULTS}

The average value ( \pm sd) of the mean sum of squares for the residual error of the fit of the Preece-Baines function to the Mayan growth data is $0.90(0.81)$ for boys and 0.60 (0.61) for girls. For the ladinos these values are $0.79(0.65)$ for boys and $0.87(0.68)$ for girls. A runs test revealed no significant pattern in the distribution of the residual errors from the fitted curve. 
TABLE 1. Mathematical and biological parameters, means, and standard deviations, of the Preece-Baines model I function for Mayan and High SES ladino boys

\begin{tabular}{|c|c|c|}
\hline Parameters & $\begin{array}{l}\text { Mayan } \\
\mathrm{n}=33\end{array}$ & $\begin{array}{c}\text { High SES ladino } \\
\mathrm{n}=78\end{array}$ \\
\hline \multicolumn{3}{|l|}{ Mathematical } \\
\hline P1 & $\begin{array}{r}169.19 \\
(4.97)\end{array}$ & $\begin{array}{r}176.90^{*} \\
(3.93)\end{array}$ \\
\hline $\mathrm{P} 2$ & 156.06 & $163.45 *$ \\
\hline & $\begin{array}{c}(4.08) \\
010\end{array}$ & (3.61) \\
\hline $\mathrm{P} 3$ & $\begin{array}{c}0.10 \\
(0.02)\end{array}$ & $\begin{array}{c}0.11 \\
(0.02)\end{array}$ \\
\hline $\mathrm{P} 4$ & 1.20 & 1.29 \\
\hline P5 & $\begin{array}{l}(0.16) \\
15.66\end{array}$ & $\begin{array}{l}(0.18) \\
13.95 \%\end{array}$ \\
\hline & $(1.04)$ & $(0.92)$ \\
\hline \multicolumn{3}{|l|}{ Biological $^{1}$} \\
\hline Height at TO & $\begin{array}{r}i 30.67 \\
(5.63)\end{array}$ & $\begin{array}{r}137.17 \\
(5.98)\end{array}$ \\
\hline Height at PHV & $\begin{array}{r}152.89 \\
(3.85)\end{array}$ & $\begin{array}{c}160.15^{*} \\
(3.44)\end{array}$ \\
\hline Age at TO & $\begin{array}{l}11.42 \\
(1.01)\end{array}$ & $\begin{array}{c}9.97 * \\
(1.05)\end{array}$ \\
\hline Age at $\mathrm{PHV}$ & $\begin{array}{l}15.26 \\
(1.06)\end{array}$ & $\begin{array}{l}13.58^{*} \\
(0.88)\end{array}$ \\
\hline Velocity at TO & $\begin{array}{c}4.08 \\
(0.51)\end{array}$ & $\begin{array}{l}4.57^{*} \\
(0.78)\end{array}$ \\
\hline Velocity at PHV & $\begin{array}{c}8.75 \\
(1.81)\end{array}$ & $\begin{array}{c}9.63 \\
(1.82)\end{array}$ \\
\hline$\%$ adult height at $\mathrm{TO}$ & $\begin{array}{l}77.24 \\
(3.88)\end{array}$ & $\begin{array}{l}77.57 \\
(3.52)\end{array}$ \\
\hline$\%$ adult height at $\mathrm{PHV}$ & $\begin{array}{l}90.40 \\
(1.45)\end{array}$ & $\begin{array}{l}90.54 \\
(1.42)\end{array}$ \\
\hline Height increment TO-PHV & $\begin{array}{l}22.32 \\
(4.57)\end{array}$ & $\begin{array}{l}22.98 \\
(3.99)\end{array}$ \\
\hline Velocity increment TO-PHV & $\begin{array}{l}4.68 \\
(2.04)\end{array}$ & $\begin{array}{l}5.07 \\
(2.02)\end{array}$ \\
\hline Height increment PHV-adult height & $\begin{array}{l}16.26 \\
(2.74)\end{array}$ & $\begin{array}{l}16.75 \\
(2.65)\end{array}$ \\
\hline
\end{tabular}

${ }^{1}$ Height and height increments in centimeters, age in years. TO, take-off; PHV, peak height velocity.

"Indicates a significant difference between the means for the Mayan and ladino samples at $P=.01$.

\section{Mean parameters of growth}

Mathematical and biological parameters of the Preece-Baines model I function for Mayan and ladino boys are presented in Table 1. Table 2 contains similar categories of data for girls. In both tables the Mayan and ladino mean values are compared statistically by the t-test, with significance set a priori at a conservative value of $P=0.01$. The significant contrasts between the Mayan and ladino boys are for the mathematical parameters P1, P2, and P5. These parameters correlate, respectively, with adult height, height at the time of PHV, and age at PHV. Significant differences between the biological parameters are for height achieved at TO and PHV, the age at which TO and PHV occurs, and the velocity of growth at TO. The ladino boys are taller at TO, at PHV, and are estimated to be taller at adulthood. The ladinos reach the age of TO 1.45 years earlier than the Mayans. The ladinos also have a greater velocity of growth in height at TO. Ladinos reach the age at PHV 1.68 years earlier than the Mayans, but the two samples of boys do not differ in growth velocity at $\mathrm{PHV}$.

It is also important to note the similarities in growth between Mayan and ladino boys. In addition to velocity at $\mathrm{PHV}$, there is no statistical difference between their mean values for percent of adult height at TO and at PHV or for increments of growth and growth velocity from TO-PHV and PHVadult height. These similarities indicate that the mean difference in height between the Mayan and ladino boys is established during the childhood growth period (i.e., prior to age at TO) and then is maintained without significant change during adolescence. 
TABLE 2. Mathematical and biological parameters of the Preece-Baines model, I function, means and standard deviations, for Mayan and high SES ladino girls

\begin{tabular}{|c|c|c|}
\hline Parameters & $\begin{array}{l}\text { Mayan } \\
\mathrm{n}=12\end{array}$ & $\begin{array}{c}\text { High SES ladino } \\
\mathrm{n}=85\end{array}$ \\
\hline \multicolumn{3}{|l|}{ Mathematical } \\
\hline P1 & $\begin{array}{c}151.81 \\
(6.28)\end{array}$ & $\begin{array}{r}162.95^{*} \\
(5.13)\end{array}$ \\
\hline $\mathrm{P} 2$ & 142.60 & $152.17 \%$ \\
\hline P3 & 0.15 & $\begin{array}{l}(4.40) \\
0.13\end{array}$ \\
\hline P4 & $\begin{array}{l}(.02) \\
1.32 \\
(0.16)\end{array}$ & $\begin{array}{c}(0.02) \\
1.24 \\
(0.14)\end{array}$ \\
\hline P5 & $\begin{array}{l}13.08 \\
(1.16)\end{array}$ & $\begin{array}{l}12.48 \\
(0.97)\end{array}$ \\
\hline \multicolumn{3}{|l|}{ Biological $^{1}$} \\
\hline Height at TO & $\begin{array}{r}123.15 \\
(5.01)\end{array}$ & $\begin{array}{r}129.65^{\sharp \mid} \\
(4.60)\end{array}$ \\
\hline Height at PHV & $\begin{array}{r}138.87 \\
(5.08)\end{array}$ & $\begin{array}{r}148.27^{\text {}} \\
(4.13)\end{array}$ \\
\hline Age at TO & $\begin{array}{c}9.81 \\
(0.92)\end{array}$ & $\begin{array}{c}8.88^{*} \\
(0.81)\end{array}$ \\
\hline Age at PHV & $\begin{array}{l}12.55 \\
(1.15)\end{array}$ & $\begin{array}{l}12.03 \\
(1.00)\end{array}$ \\
\hline Velocity at TO & $\begin{array}{c}4.97 \\
(1.80)\end{array}$ & $\begin{array}{c}4.93 \\
(0.76)\end{array}$ \\
\hline Velocity at PHV & $\begin{array}{c}7.22 \\
(1.91)\end{array}$ & $\begin{array}{c}7.78 \\
(1.06)\end{array}$ \\
\hline$\%$ adult height at $\mathrm{TO}$ & $\begin{array}{l}81.20 \\
(3.43)\end{array}$ & $\begin{array}{l}79.60 \\
(2.83)\end{array}$ \\
\hline$\%$ adult height at PHV & $\begin{array}{l}91.52 \\
(1.84)\end{array}$ & $\begin{array}{l}91.01 \\
(1.08)\end{array}$ \\
\hline Height increment TO-PHV & $\begin{array}{l}15.72 \\
(3.16)\end{array}$ & $\begin{array}{l}18.61^{*} \\
(3.46)\end{array}$ \\
\hline Velocity increment TO-PHV & $\begin{array}{l}2.25 \\
(0.90)\end{array}$ & $\begin{array}{l}2.84 \\
(1.21)\end{array}$ \\
\hline Height increment PHV-adult height & $\begin{array}{l}12.93 \\
(3.17)\end{array}$ & $\begin{array}{l}14.68^{*} \\
(2.02)\end{array}$ \\
\hline
\end{tabular}

${ }^{1}$ Height and height increments in centimeters, age in years. TO, take-off; PHV, peak height velocity.

* Indicates a significant difference between the means for the Mayan and ladino samples at $P=.01$.

Mayan and ladina girls are similar in velocity at $\mathrm{TO}$, the velocity increment from TO-PHV, and in percent of adult height at TO and at PHV. The two groups of girls show statistically significant differences between the mathematical parameters $\mathrm{P} 1$ and $\mathrm{P} 2$, and between the biological parameters height at TO, height at PHV, age at TO, height increment TO-PHV, and height increment PHV-adult height. Mayan girls are, on average, $6.50 \mathrm{~cm}$ shorter at age at $\mathrm{TO}$ despite the fact that they grow for 0.93 years longer than ladina girls prior to age at TO. The difference in mean height established during childhood increases during adolescence to $9.40 \mathrm{~cm}$ at age at PHV, and to an estimated $11.14 \mathrm{~cm}$ at adulthood. The mean disparity increases with time because the Mayan girls, unlike their male counterparts, are similar to the ladina girls in the timing of PHV and grow significantly less than ladina girls during adolescence.

\section{Sex related differences in growth pattern}

Presented in Figure 1 is the pattern of contrast of the biological parameters between boys and girls of the Mayan and $l a-$ dino samples. Positive values indicate that the ladino parameter means are greater than the Mayan means. Negative values indicate that Mayan parameter values are greater. The data were transformed to normalized z-scores to remove units of measurement (i.e., $\mathrm{cm}, \mathrm{cm} /$ year, age in years, and percent) and allow direct comparison between all parameters. This figure helps to visualize the interaction between 


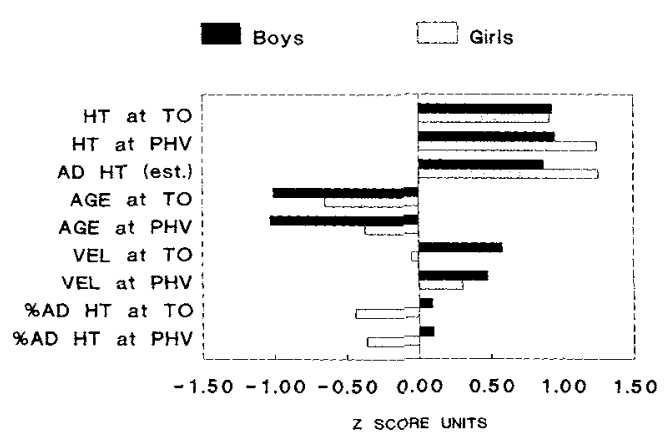

Fig. 1. Mean difference in the value of biological parameters between ladino and Mayan boys and girls expressed in $\mathrm{z}$-score units. Positive values indicate that the ladino means are larger than the Mayan means. Negative values indicate that the Mayan mean parameters are larger. $\mathrm{HT}=$ height, $\mathrm{TO}=$ take-off, $\mathrm{PHV}=$ peak height velocity, $\mathrm{AD}=$ adult.

ETHNICITY/SES, on the one hand, and SEX, on the other hand, as factors that influence growth during childhood and adolescence. ETHNICITY and SES are confounded in these samples of Mayan and ladino children, and we make no attempt here to ascertain the unique contribution of each variable to growth. A two-way analysis of variance (ETHNIC/SES group by SEX) was performed to quantify the main effects and the interactions.

There are significant differences for the main effect of SEX for each of the biological parameters. Significant ETHNIC/SES differences exist for all parameters except velocity at $\mathrm{TO}$, percent adult height at $\mathrm{TO}$, and percent adult height at PHV. A significant ETHNIC/SES by SEX interaction is found for age at PHV: ladino and Mayan boys differ significantly but ladina and Mayan girls do not differ. The cause of this interaction seems to be that Mayan girls move from age at TO to age at PHV more rapidly than the Mayan boys. Compared with ladino boys, the Mayan boys' delay for age at TO (1.45 years) is less than the delay for age at PHV (1.68 years). In contrast, relative to ladina girls the Mayan girls' delay in age at TO (0.93 years) is greater than the delay for age at $\mathrm{PHV}(0.52$ years $)$.

Thus, the Mayan girls' more rapid movement through adolescence, along with a

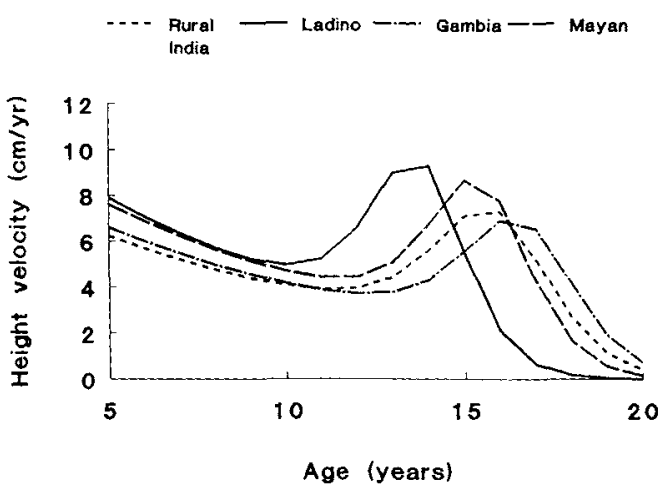

Fig. 2. Mean-constant velocity curves for height by age for boys.

slower rate of growth at all ages, accounts for their increasing disparity in size at age at TO, PHV, and adulthood compared with the ladina girls. In a similar way, the rapid development of the Mayan girls during adolescence also accounts for the increasing size difference between them and the Mayan boys (compare the Mayan means in Tables 1 and 2).

\section{Population differences in the velocity and timing of growth events}

The mean-constant velocity curves of growth for Mayan and ladino boys are displayed graphically in Figure 2. In addition, curves for rural Indian boys (Satyanarayana et al., 1989) and rural Gambiar boys (Billewicz and McGregor, 1982) are shown to place the growth of the Guatemalans in international context. Both the rural Indians (from the Hyderabad region of India) and the Gambians are described as suffering from poor living conditions, high rates of disease, and chronic undernutrition. The same estimation model was used to apply the Preece-Baines function to the growth of all of these samples to ensure comparability of the parameter estimates. In contrast to the high SES ladino boys, who are generally healthy and well nourished, the Mayan, rural Indian, and rural Gambian boys have slower velocities of growth during childhood and adolescence. These three slower growing groups also have a longer period of childhood and adolescent growth; note that the 


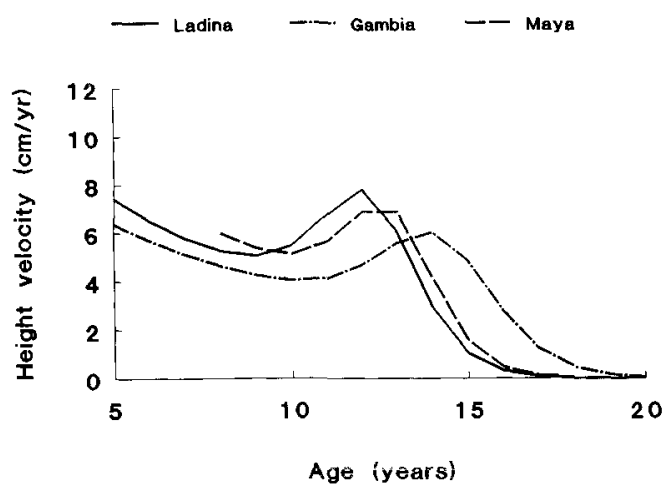

Fig. 3. Mean-constant velocity curves for height by age for girls.

Preece-Baines function estimates that growth continues beyond age 20 years. Despite this the Mayans, Indians, and Gambians end up significantly shorter than the high SES ladinos (estimated adult height for the Indian men is $158.2 \mathrm{~cm}$ and for the Gambian men $170.8 \mathrm{~cm}$ ).

In Figure 3 are mean-constant velocity curves for ladina girls, Mayan girls, and rural Gambian girls. The Mayan curves start at age 8 because there were no cases under age 7 and there was only one girl at age 7 . Compared with ladina girls, the Mayan and Gambian girls show a general pattern of slower growth and delayed maturation, although this is more pronounced for the Gambians. An exception to this general pattern is that Mayan girls grow more rapidly than the ladina girls at age 8. Despite that anomaly, Mayan and Gambian girls are shorter at all ages, including adulthood, than ladina girls (the estimated adult height of the Gambian women is $158.8 \mathrm{~cm}$ ).

\section{DISCUSSION}

Although the sample sizes for the Mayan children are small, especially for the girls, data on the growth of Native American children are scarce. Accordingly, we offer the results of this study as a tentative first analysis of the longitudinal growth of Mayan children during adolescence. The use of the Preece-Baines model increases the reliabil- ity of the analysis of these limited Mayan data. The model assumes the shape of the adolescent curve of growth in height and, in a sense, forces the data to conform to that shape (Marubini and Milani, 1986). This may obscure information about patterns of growth that do not conform to the constraints of the parameters of the model (Bogin, 1988). However, the process of fitting the data to a predetermined model means, theoretically, that sets of longitudinal measurements for individual children that are incomplete (i.e., missing values or not covering the whole growth period) can still be analyzed.

It is clear that in comparison with the high SES ladinos the low SES Mayans experience a reduction in the amount of growth and in the velocity of growth at many ages. Mayan boys, and to a lesser extent Mayan girls, also show delays in the timing of developmental milestones, such as TO and PHV. These results are in general agreement with the findings of the earlier mixed-longitudinal study of these same school populations (Bogin et al., 1989). That earlier study was based on much larger samples for the Mayan children ( 171 boys and 90 girls), and the similarity in findings increases confidence in the result of the present analysis. Velocity at PHV is a notable exception to the general tendency for Mayans and ladinos to differ. However, little should be made of this since velocity at PHV is but an instant in the total duration of childhood and adolescent growth. Indeed, Largo et al. (1978) show that velocity at $\mathrm{PHV}$ is not correlated with adult height.

A more important similarity between Mayans and ladinos is the percent of adult height achieved at both TO and at PHV. It is not easy to understand how these percentages are essentially identical for two groups of children differing in ethnicity, SES, sex, and by their patterns of growth during childhood and adolescence. Perhaps this similarity in percentage tells us something about universal biological mechanisms for growth regulation, or maybe it merely tells us something about the manner by which the PreeceBaines function forces the data to conform to an a priori determined growth curve. 
The difference in height between Mayans and ladinos may be due, in part, to genetic determinants of amount of growth. However, it is not possible to assess that determination in these samples. Moreover, an explanation that relies heavily on the genetic limitation of Mayan growth is not particularly useful. The low SES of the Mayans, as measured by a questionnaire for parental occupation and education and by ethnographic observation, correlates with their chronic mild-to-moderate undernutrition, higher rates of disease, and generally unfa vorable environment for growth. In this regard the Mayan pattern of growth in height is similar to that of other disadvantaged populations, such as the rural Indians and Gambians depicted in Figures 2 and 3. The result is shorter stature at all stages of growth for the Mayans, Indians, and Gambians compared with the high SES ladinos. Because of the wide geographic, ethnic, and sociocultural differences between these groups (perhaps genetic differences too), it seems that it is the shared negative environment for growth that produces the similar pattern in amount and rate of growth in height in the Mayan, Indian, and Gambian samples.

The overall environmental effect interacts with sex in that the difference in height between Mayan and ladino boys is established during childhood and remains fairly constant during adolescence and at adulthood. In contrast, the difference in height between the Mayan and ladina girls increases from childhood to adolescence and reaches its maximum at adulthood. The cause of this interaction is not known. However, the joint effect of two hypotheses about human growth may be considered to propose a reason for the interaction. One hypothesis is that growth during childhood is more sensitive to environmental factors and growth during adolescence is determined more by genetic factors (reviewed by Bogin, 1988). Of course, growth at all stages of development is controlled by the interaction of genetic and environmental factors. So, it is more accurate to state that this hypothesis apportions the relative weight of the contribution of genes and environment to this interaction differently during the childhood and adolescent stages of growth. The other hypothesis is that girls are better "buffered" against environmental determinants of growth, especially negative influences such as undernutrition and disease, than boys (reviewed by Stinson, 1985).

The first hypothesis predicts the observation that Mayan boys and girls are shorter than ladino children during childhood. The environment for growth of the low SES Mayans may be so powerfully negative that despite the girls' "buffering" (hypothesis 2) their growth deficit is about the same as that for the Mayan boys. Some evidence of that buffering does exist, in that the Mayan and ladina girls do not differ in growth velocity at the age of TO, but Mayan and $l a$ dino boys do differ. Neither Mayan boys nor girls differ from ladino boys or girls in the velocity of growth at PHV. That may be evidence of the relatively stronger contribution of a genetic determination of growth at that time. However, compared with ladinos the Mayan boys continue to show developmental delays; for instance, a later age at PHV. The Mayan boys' delayed maturation is likely due to the continuation of the negative environmental milieu in which they live. The developmental delay is not prolonged enough to compensate for the reduced rate of growth during childhood. Consequently, the height difference between Mayan and ladino boys is maintained until adulthood.

In contrast to the Mayan boys, Mayan girls do not experience a significant delay in maturation during adolescence. Perhaps this is due to the girls' genetic "buffering" against the environment combined with the relatively greater genetic determination of growth at adolescence. These two genetic factors working together may override the maturation delaying effects of the environment. Thus, Mayan girls proceed through adolescence more rapidly; that is, more in accordance with the genetically determined timing for development, than the Mayan boys. The Mayan girls' amount of growth is less than that of the ladina girls during adolescence because the Mayans have a shorter time interval between TO and PHV. As a result, the difference in height between 
Mayan and ladina girls increases to a greater extent than the difference in height between Mayan and ladino boys.

The application of these two hypotheses to the patterns of childhood and adolescent growth of these Mayan children is speculative. Of course, further research to test the validity of this application is required. Nevertheless, if the goal of scientific research is to both discover patterns in our observations of nature and also discover the causes of these patterns, then this attempt to apply two hypotheses of growth to the Mayan pattern of development is worthwhile.

\section{ACKNOWLEDGMENTS}

Thanks to Prof. Maciej Henneberg and Dr. Babette Zemel for comments that improved the presentation of this analysis.

\section{LITERATURE CITED}

Annis S (1987) God and Production in a Guatemalan Town. Austin: University of Texas Press.

Billewicz WZ, and McGregor IA (1982) A birth to maturity longitudinal study of heights and weights in two West African (Gambian) villages. Ann. Hum. Biol. 9:309-320.

Boas F (1930) Observations on the growth of children. Science 72:44-48.

Bogin B (1988) Patterns of Human Growth. Cambridge: Cambridge University Press.

Bogin B, and MacVean RB (1978) Growth in height and weight of urban Guatemalan primary school children of high and low socioeconomic class. Hum. Biol. $50: 477-488$.

Bogin B, and MacVean RB (1981) Body composition and nutritional status of urban Guatemalan children of high and low socioeconomic status. Am. J. Phys. Anthropol. 55:543-51.

Bogin, B., and MacVean RB (1983) The relationship of socioeconomic status and sex to body size, skeletal maturation, and cognitive status of Guatemala city school children. Child Dev. 54:115-128.

Bogin B, and MacVean RB (1984) Growth status of nonagrarian, semi-urban living Indians in Guatemala. Hum. Biol. 56:527-538.

Bogin B, and Sullivan T (1986) Socioeconomic status, sex, age, and ethnicity as determinants of body fat distribution for Guatemalan children. Am. J. Phys. Anthropol. 69:527-535.

Bogin B. Sullivan T, Hauspie R, and MacVean RB (1989) Longitudinal growth in height, weight, and bone age of Guatemalan Ladino and Indian schoolchildren. Am. J. Hum. Biol. 1:103-113.

Bogin, B, Wall M, and MacVean RB (1990) Longitudinal growth of high socioeconomic status Guatemalan chil- dren analyzed by the Preece-Baines function: An international comparison. Am. J. Hum. Biol. 2:271-281.

Bossert, TJ, and Peralta E del Cid (1987) Guatamala Health Sector Assessment 1987 Update. Guatemala: USAID Mission in Guatemala.

Brown T (1983) The Preece-Baines growth function demonstrated by personal computer: A teaching and research aid. Ann. Hum. Biol. 10:487-489.

Cameron N (1986) The methods of auxological anthropology. In F Falkner and JM Tanner (eds.): Human Growth, Vol. 3. Second edition. New York: Plenum, pp. 3-46.

Carmack R (ed.) (1988) Harvest of Violence: The Maya Indians and the Guatemalan Crisis. Norman: University of Oklahoma Press.

INCAP (1969) Evaluacion nutricional del la poblacion de Centro America y Panama. Guatemala City: Institute of Nutrition of Central America and Panama.

INCAP (1989) Encuesta Nacional de Salud Materno Infantil. Guatemala City: Institute of Nutrition of Central America and Panama.

Johnston FE, Bogin B, MacVean RB, and Newman BC (1984) A comparison of international standards versus local reference data for the triceps and subscapsular skinfolds of Guatemalan children and youth. Hum. Biol. 56:157-171.

Johnston FE, Borden M, and MacVean RB (1973) Height, weight and their growth velocities in Guatemalan private schoolchildren of high socioeconomic class. Hum. Biol. 45:627-641.

Largo RH, Gasser Th, Prader A, Stutzle W, and Huber PJ (1978) Analysis of the adolescent growth spurt using smoothing spline functions. Ann. Hum. Biol 5:421-434.

Marubini E, and Milani S (1986) Approaches to the analysis of longitudinal data. In F Falkner and JM Tanner (eds.): Human Growth, Vol. 3. Second edition. New York: Plenum, pp. 79-109.

May JM and McLellan DL (1972) The Ecology of Malnutrition in Mexico and Central America. New York: Hafner.

Mendez J, and Berhorst C (1963) The anthropometric characteristics of Indians and urban Guatemalans. Human Biol. 36:457-469.

Pettersen CL (1976) Maya of Guatemala: Life and Dress. Guatemala: Ixchel Textile Museum, pp. 162 178.

Preece MA, and Baines MJ (1978) A new family of mathematical models describing the human growth curve. Ann. Hum. Biol. 5:1-24.

Preece MA, and Metcalf K (1985) The robusticity of the Preece-Baines function (abstract). Ann. Hum. Biol. Suppl. 1 12:85.

Sabharwal KP, Morales S, and Mendez J (1966) Body measurements and creatinine excretion among upper and lower socioeconomic groups of girls in Guatamala. Hum. Biol. 38:131-140.

Satyanarayana K, Radhaiah G, Murali Mohan KR, Thimmayamma BVS, Pralhad Rao N, and Narasinga Rao BS (1989) The adolescent growth spurt of height among rural Indian boys in relation to childhood nu- 
tritional background: An 18 year longitudinal study. Ann. Hum. Biol. 16:289-300.

Siverts H (1969) Ethnic stability and boundary dynamics in Southern Mexico. In F Barth (ed.): Ethnic Groups and Boundaries. Boston: Little, Brown, pp. 101-116.
Stinson S (1985) Sex differences in environmental sensitivity during growth. Yearbook of Phys. Anthropol. 28:123-147.

Tedlock B (1982) Time and Highland Maya, Albuquerque: University of New Mexico Press. 